Audiology

Neurotology
Audiol Neurotol 2019;24:90-99

DOI: $10.1159 / 000499363$
Received: October 2, 2018

Accepted after revision: February 28, 2019

Published online: May 29, 2019

\title{
The Bonebridge in Adults with Mixed and Conductive Hearing Loss: Audiological and Quality of Life Outcomes
}

\author{
Piotr H. Skarżyński ${ }^{a-c}$ Anna Ratuszniak ${ }^{d}$ Bartłomiej Król $^{d} \quad$ Magdalena Koziełe $^{\mathrm{e}}$ \\ Kamila Osińskad Katarzyna B. Cywkad Anna Sztabnickad Henryk Skarżyńskid \\ ${ }^{a}$ Heart Failure and Cardiac Rehabilitation Department, Second Faculty of the Medical University of Warsaw, \\ Warsaw, Poland; ${ }^{\mathrm{b}}$ Institute of Sensory Organs, Kajetany, Poland; ' Department of Teleaudiology and Screening, \\ World Hearing Center, Institute of Physiology and Pathology of Hearing, Kajetany, Poland; ${ }^{d}$ Otorhinolaryngosurgery \\ Clinic, World Hearing Center, Institute of Physiology and Pathology of Hearing, Kajetany, Poland; ${ }^{e}$ Clinical Studies, \\ Institute of Sensory Organs, Kajetany, Poland
}

\section{Keywords}

Bonebridge · Implantation · Quality of life · Benefits · Bone conduction

\section{Abstract \\ Background: Considering that hearing loss has a significant impact on social functioning, everyday activity and a per- son's emotional state, one of the most important goals of hearing rehabilitation with bone conduction devices is im- provement in a patient's quality of life. Objectives: To mea- sure self-assessed quality of life in patients implanted with the Bonebridge, a bone conduction device. Method: Pro- spective, observational, longitudinal study with one treat- ment group. Twenty-one patients with mixed or conductive hearing loss were included, and each individual served as its own control. The Abbreviated Profile of Hearing Aid Benefit (APHAB) was used to measure patient-reported quality of life before intervention and at 3 and 6 months after activation of the device. At the same time frames, pure-tone audiometry and speech understanding in quiet and in noise were tested. Results: Hearing-specific quality of life increased significant- ly after intervention and remained stable up to 6 months.}

Both word recognition in quiet and speech reception threshold in noise were significantly better after 6 months compared to before surgery. Outcomes of aided speech understanding were independent of initial bone conduction thresholds and equally high (word recognition score $>75 \%$ ) across the device's indication range. Conclusions: The Bonebridge provides not only significant audiological benefit in both speech understanding in quiet and in noise, but also increases self-perceived quality of life in patients suffering from mixed and conductive hearing loss. Together with a very low rate and minor nature of adverse events, it is the state-of-the-art solution for hearing rehabilitation in patients with mixed or conductive hearing loss up to a bone conduction threshold of $45 \mathrm{~dB} \mathrm{HL}$.

$$
\begin{aligned}
& \text { () } 2019 \text { The Author(s) } \\
& \text { Published by S. Karger AG, Basel }
\end{aligned}
$$

\section{Introduction}

The causes of conductive or mixed hearing loss are manifold, include various pathologies (congenital atresia, chronic otitis media, cholesteatoma, otosclerosis) and are often associated with complex surgical histories. Differ-

\begin{tabular}{ll}
\hline KARGER & $\begin{array}{l}\text { (c) } 2019 \text { The Author(s) } \\
\text { Published by S. Karger AG, Basel }\end{array}$ \\
E-Mail karger@karger.com & $\begin{array}{l}\text { This article is licensed under the Creative Commons Attribution- } \\
\text { NonCommercial-NoDerivatives 4.0 International License (CC BY- } \\
\text { NC-ND) (http://www.karger.com/Services/OpenAccessLicense). } \\
\text { Nww.karger.com/aud }\end{array}$ \\
$\begin{array}{l}\text { Usage and distribution for commercial purposes as well as any dis- } \\
\text { tribution of modified material requires written permission. }\end{array}$
\end{tabular}

Piotr H. Skarżyński

Institute of Sensory Organs Mokra 1 Street

PL-05-830 Kajetany (Poland)

E-Mail p.skarzynski@inz.waw.pl 
ent options for hearing rehabilitation exist for these patients [Gavilan et al., 2015; Ratuszniak et al., 2017], including traditional hearing aids, surgical rehabilitation (e.g., ossiculoplasty), bone conduction implants (BCIs) and middle-ear implants [Olszewski et al., 2017]. While traditional hearing aids provide insufficient amplification to many of these patients [Braun et al., 2014; Alzahrani et al., 2015], the audiological benefit of surgical hearing restoration has been shown to be limited compared to BCIs in some conditions (e.g., in atresia patients) [Nadaraja et al., 2013]. Also, surgical hearing restoration can be associated with a relatively high risk of revision surgeries [Gardner et al., 2004; Govil et al., 2017]. Conversely, both BCIs and middle-ear implants are excellent treatment options, and it is up to the surgeon to balance pros and cons for each patient individually.

Recent years have seen a dynamic development in the field of implantable bone conduction (BC) hearing implants as manufacturers developed transcutaneous devices in an attempt to overcome the elevated incidence of dermatological complications known from classical, percutaneous bone-anchored hearing implants [Wazen et al., 2011]. The latest technological solution - active BC devices - is represented on the market by only one device, the Bonebridge (MED-El, Innsbruck, Austria), which has been introduced in 2012. This semi-implantable system consists of two components: an active, implantable part (BCI) and an externally worn audioprocessor. Sound is transmitted from the audioprocessor to the $\mathrm{BCI}$, where it is converted into mechanical vibration that is directly applied to the skull bone via the bone conduction floating-mass transducer (BC-FMT). Like in other devices, the audioprocessor is held in place by magnetic force. However, since the active (vibrating) part is implanted, less force is needed to hold the audioprocessor in place. Due to the active design, damping caused by skin and soft tissues, as known from other transcutaneous devices, is eliminated. Additional features differentiating this implant from other implantable solutions are: method of fixation of the subcutaneous vibrating transducer (with two dedicated screws) and size of the implanted part (size of the BC-FMT: diameter $15.8 \mathrm{~mm}$, height $8.7 \mathrm{~mm}$ ). The system can be used in patients with conductive or mixed hearing loss, whose $\mathrm{BC}$ thresholds are not higher than $45 \mathrm{~dB}$ HL for 500, 1,000, 2,000 and $3,000 \mathrm{~Hz}$ in the ear to be implanted, or, in cases of singlesided deafness, in the ear with a severe to profound hearing loss and contralateral normal hearing [Sprinzl et al., 2013; Riss et al., 2014]. Other inclusion criteria are: age above 5 years (since 2014), stable BC thresholds and re-

The Bonebridge in Adults: Audiological and Quality of Life Outcomes alistic expectations. Due to the size of the vibrating transducer, another important factor is that the anatomy of the mastoid allows a safe placement of the BCI. For this reason, the surgical procedure for implantation of this device is considered more difficult compared to other solutions, especially in the case of patients with extensive bone loss due to previous surgeries in the mastoid area. In these patients it is recommended to perform a CT scan before making a decision about surgery [Weiss et al., 2017a].

The introduction of a new treatment solution is an occasion to pose questions about the effectiveness of compensating conductive and mixed hearing loss, long-term clinical effects of the device use and safety of use. Although audiological results of the Bonebridge that have been published by other authors from different centres indicate that it is a safe and highly efficient solution [Sprinzl et al., 2013; Ihler et al., 2014; Laske et al., 2015; Rahne et al., 2015; Baumgartner et al., 2016; Schmerber et al., 2017; Weiss et al., 2017b; Bravo-Torres et al., 2018], these were mainly based on small patient groups. One aim of this study is thus to assess the effectiveness of the Bonebridge system in a larger patient group with conductive or mixed hearing loss and complex patient histories.

Considering that hearing loss has a significant impact on social functioning, everyday activity and the patient's emotional state, one of the most important goals of this medical intervention is improvement in a patient's quality of life. A second aim of this study is thus the assessment of pre- versus postintervention benefits in hearingrelated quality of life (QoL).

\section{Materials and Methods}

\section{Study Design}

This study was designed as prospective follow-up study with each patient's pre-operative unaided outcomes serving as control. The study protocol was approved by the Institutional Review Board of the Institute of Physiology and Pathology of Hearing (IFPS:/KB/05/2014) and conformed with the Declaration of Helsinki. Between July 2014 and August 2016, 25 patients were included.

\section{Surgery}

For all patients, CT scans were carried out in order to evaluate optimal positioning of the BC-FMT in the mastoid bone. All surgeries were conducted under general anaesthesia following standard procedures suggested by the manufacturer of the device. After confirmation by CT scans, the Bonebridge implant was placed in the sinodural angle in all cases (Fig. 1). In patients after the radical operation, the cavities were obliterated with the bioactive glass 


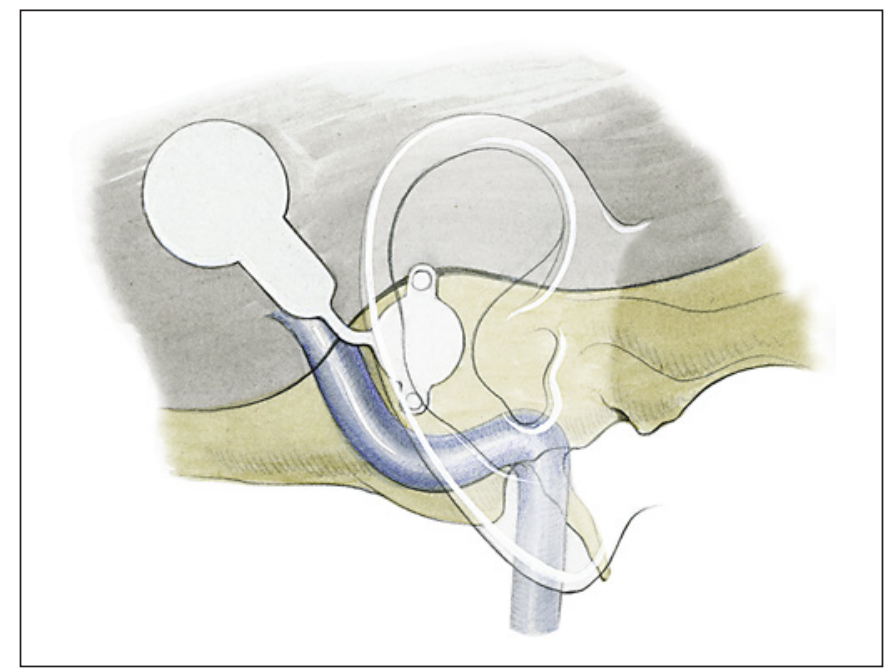

Fig. 1. The sinodural positioning of the BC-FMT. Copyright by MED-El.

(BonAlive) before implantation of the Bonebridge system. Whenever needed, spacers (BCI lifts; available in 1, 2, 3 or $4 \mathrm{~mm}$ height from the manufacturer) were positioned under the transducer wings to allow for lower drilling depth.

\section{Audiometric Testing}

Audiometric tests were performed with an Otometrics Madsen Itera II diagnostic audiometer before implantation of the Bonebridge as well as 3 and 6 months after first fitting of the device. At each time interval, air conduction and BC thresholds, sound field thresholds, word recognition score (WRS) and speech reception thresholds in noise were measured - with the exception that speech reception threshold in noise was not measured at the 3-month interval. All tests were performed in an anechoic chamber. Sound field thresholds were measured using warble tones presented from a loudspeaker that was situated $1 \mathrm{~m}$ in front of the subject. The WRS was assessed with the Demenko \& Pruszewicz Polish Monosyllabic Word Test at 50, 60 and $70 \mathrm{~dB}$ SPL presented via a loudspeaker. The contralateral ear was double-blocked with an earplug and over-earphone or masked with noise if necessary. Speech reception thresholds in noise were assessed using the Polish Matrix Sentence Test with signal and noise presented from the front (S0N0). The noise level was fixed at $65 \mathrm{~dB}$ SPL.

\section{QoL Questionnaire}

Patient-reported outcomes were collected using the Abbreviated Profile of Hearing Aid Benefit (APHAB; hearing-specific QoL by Cox and Alexander [1995]) The APHAB is the most widely used hearing-specific questionnaire and was chosen for comparability with other studies. The unit reported is the amount of problems in percent. Thus, lower values indicate better outcomes. A global score and 4 subscores can be calculated for ease of communication, background noise, reverberation and aversiveness to sound.

\section{Statistical Analyses}

The Friedman test was used to test for significance of overall effects among blocks of paired data. Whenever missing data were present, a generalized version of the Friedman test, the SkillingsMack test [Chatfield and Mander, 2009], was used. The Wilcoxon signed-rank test and the Holm $p$ value adjustment were used for pairwise comparisons. The $\alpha$-level was set to 0.05 . All statistical tests were performed in $R$ v3.4.1 statistical computing environment [R Core Team, 2015] via the graphical user interface RStudio v1.0.136. All plots were built using the ggplot2 package [Wickham, 2009].

\section{Results}

\section{Patient Demographics}

Between 2014 and 2016, 25 consecutive patients were included in this prospective study. Three patients were lost to follow-up, and 1 patient was excluded due to inconsistent outcomes. Different measuring stations were used in the latter case and that may have biased measurements at the pre-operative time frame. The final population included 21 patients (21 ears). Demographic information is summarized in Table 1. Age at implantation ranged from 18 to 58 years with a mean of 40.29 years $(\mathrm{SD}=13.64)$. There were 8 patients with conductive and 13 patients with mixed hearing loss. In 8 patients, the hearing loss was bilateral, but all patients were unilaterally implanted in this study. The causes of hearing loss in these patients include chronic otitis media, cholesteatoma, otosclerosis or congenital malformations of the middle or outer ear.

\section{Surgical Outcomes and Adverse Events}

CT scans favoured the placement of the BC-FMT in the sinodural position in all patients. No adverse events were observed during surgeries. In 1 case, sclerotic and extremely hard mastoid bone was observed. BCI lifts were used in 8 patients $(3 \times 1 \mathrm{~mm}, 4 \times 2 \mathrm{~mm}, 1 \times 3 \mathrm{~mm}$ lift size; Table 1 ), and in 1 case, self-tapping screws were used. In 1 case the dura was exposed, and a small bone plate was placed between dura and implant to prevent direct pressure from the BC-FMT. Besides 1 case of slight swelling, no further complications were noted in the immediate postoperative period.

No major adverse events occurred up to the 6-month follow-up. In total, 8 patients experienced minor adverse events: patient 2 had pain at the audioprocessor site at 3 months of follow-up. Following change of magnet strength, the pain was gone at 6 months of follow-up. Patient 3 had a feeling of numbness and tingling at the implant site 1 month after surgery. These symptoms were decreasing after 3 months without any treatment and were absent at the 6 -month follow-up. Patient 6 had pain 
Table 1. Patient demographics

\begin{tabular}{|c|c|c|c|c|c|c|c|c|}
\hline Patient & $\begin{array}{l}\text { Age at } \\
\text { implantation, } \\
\text { years }\end{array}$ & Sex & $\begin{array}{l}\text { Implant } \\
\text { side }\end{array}$ & $\begin{array}{l}\mathrm{HL} \\
\text { type }\end{array}$ & $\begin{array}{l}\mathrm{HL} \\
\text { side }\end{array}$ & Cause of HL & $\begin{array}{l}\text { BCI } \\
\text { lift type }\end{array}$ & $\begin{array}{l}\text { Previous surgery } \\
\text { (implanted side) }\end{array}$ \\
\hline 1 & 55 & $\mathrm{~F}$ & Right & MHL & Bilateral & $\begin{array}{l}\text { Bilateral COM; } \\
\text { cholesteatoma left }\end{array}$ & No & $3 \times$ tympanoplasty \\
\hline 2 & 41 & $\mathrm{~F}$ & Left & MHL & Left & Microtia/atresia & No & Plastic surgery of the pinna \\
\hline 3 & 45 & $\mathrm{~F}$ & Right & MHL & Right & $\begin{array}{l}\text { Congenital defect outer and } \\
\text { middle ear }\end{array}$ & No & No \\
\hline 4 & 18 & M & Right & CHL & Right & Congenital defect outer ear & No & $\begin{array}{l}4 \times \text { plastic surgery of the pinna } \\
\text { (surgery divided into } 4 \text { stages) }\end{array}$ \\
\hline 5 & 56 & $\mathrm{~F}$ & Right & MHL & Bilateral & Otosclerosis & No & $\begin{array}{l}\text { Stapedotomy, revision with } \\
\text { removal of adhesions from middle ear }\end{array}$ \\
\hline 6 & 56 & M & Right & MHL & Bilateral & $\mathrm{COM}$ & No & Myringoplasty \\
\hline 7 & 22 & M & Right & MHL & Bilateral & $\begin{array}{l}\text { Congenital defect } \\
\text { outer and middle ear }\end{array}$ & No & $\begin{array}{l}\text { Reconstructing the auditory } \\
\text { canal + myringo-ossiculoplasty }\end{array}$ \\
\hline 8 & 55 & M & Left & MHL & Bilateral & $\mathrm{COM}$ & No & Myringoplasty, ossiculoplasty \\
\hline 9 & 58 & $\mathrm{~F}$ & Right & MHL & Bilateral & $\mathrm{COM}$ & $3 \mathrm{~mm}$ & Myringo-ossiculoplasty \\
\hline 10 & 56 & $\mathrm{~F}$ & Left & $\mathrm{CHL}$ & Left & COM; cholesteatoma & $2 \mathrm{~mm}$ & $2 \times$ myringo-ossiculoplasty \\
\hline 11 & 41 & M & Left & MHL & Bilateral & COM; cholesteatoma & $2 \mathrm{~mm}$ & Radical mastoidectomy \\
\hline 12 & 56 & M & Left & MHL & Bilateral & $\mathrm{COM}$ & $2 \mathrm{~mm}$ & Radical mastoidectomy \\
\hline 13 & 18 & M & Right & MHL & Right & $\begin{array}{l}\text { Congenital defect } \\
\text { outer and middle ear }\end{array}$ & No & Plastic surgery of the pinna \\
\hline 14 & 37 & $\mathrm{~F}$ & Left & MHL & Left & COM; cholesteatoma & No & $\begin{array}{l}2 \times \text { cholesteatoma removal, } \\
\text { ossiculoplasty }\end{array}$ \\
\hline 15 & 36 & $\mathrm{~F}$ & Right & $\mathrm{CHL}$ & Right & COM; cholesteatoma & No & Ossiculoplasty \\
\hline 16 & 29 & $\mathrm{~F}$ & Left & $\mathrm{CHL}$ & Left & $\mathrm{COM}$ & $1 \mathrm{~mm}$ & Tympanoplasty with ossiculoplasty \\
\hline 17 & 32 & M & Left & CHL & Left & Atresia & $2 \mathrm{~mm}$ & Plastic surgery of the ear canal \\
\hline 18 & 30 & $\mathrm{~F}$ & Right & $\mathrm{CHL}$ & Right & Congenital defect outer ear & $1 \mathrm{~mm}$ & No \\
\hline 19 & 18 & M & Right & CHL & Right & Congenital defect outer ear & No & No \\
\hline 20 & 41 & $\mathrm{~F}$ & Left & MHL & Left & $\mathrm{COM}$ & No & Tympanotomy + myringoplasty \\
\hline 21 & 46 & M & Left & $\mathrm{CHL}$ & Left & $\mathrm{COM}$ & $1 \mathrm{~mm}$ & Radical mastoidectomy \\
\hline
\end{tabular}

HL, hearing loss; BCI, bone conduction implant; F, female; M, male; CHL, conductive hearing loss; MHL, mixed hearing loss; COM, chronic otitis media.

at the implant site and discharge from the ear. The symptoms were not resolved at the 6-month follow-up, and the patient was referred to a hospital where he was treated for otitis media with corticosteroid ointment and local antibiotics. Patient 7 had discharge from the implanted ear 1 month after surgery, but this resolved without treatment and was no longer present at the 3-month followup. Patient 9 reported mild dizziness when moving at 3 months of follow-up, but this resolved without treatment. The patient was referred to consultation for suspected problems with blood pressure, and subsequently hypertension treatment was applied. Patient 13 had slight swelling during the healing process, but this resolved before the 1-month follow-up without any special treatment. Patient 18 had discharge from the implanted ear at the 3 -month follow-up, which was resolved at 6 months. Pa- 
Fig. 2. Bone conduction (BC) threshold stability over 6 months of follow-up. Paired samples are connected by lines. Mean and median are given as crosses and horizontal lines, respectively. Boxes give 25 and $75 \%$ quartiles. Whiskers denote minimum/ maximum values but do not include outliers, which are defined as values deviating more than \pm 1.5 times the interquartile range from the respective quartiles. PTA4, pure tone average $(0.5,1,2$ and $4 \mathrm{kHz})$; ns, not significant; NA, not available.
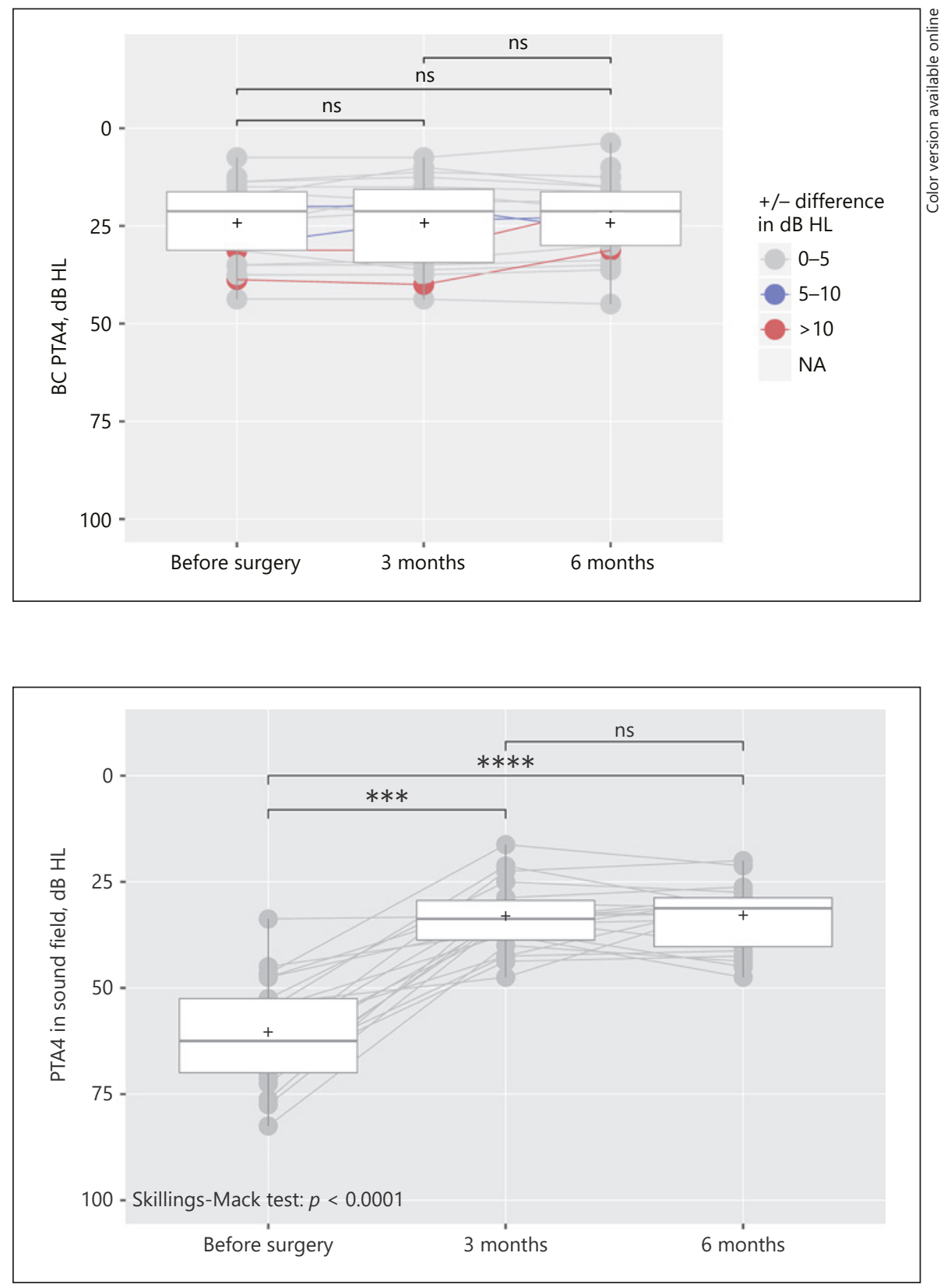

Fig. 3. PTA4 of sound field thresholds (warble tones) over 6 months of follow-up. Paired samples are connected by lines. Mean and median are given as crosses and horizontal lines, respectively. Boxes give 25 and $75 \%$ quartiles. Whiskers denote minimum/maximum values but do not include outliers, which are defined as values deviating more than \pm 1.5 times the interquartile range from the respective quartiles. PTA4, pure tone average $(0.5,1,2$ and $4 \mathrm{kHz})$; ns, not significant; ${ }^{* * *} p \leq 0.001$; $^{* * * *} p \leq$ 0.0001 . tient 19 had problems accepting the device immediately after surgery. However, acceptance was good during the further follow-up period.

\section{Audiometry and Speech Tests}

BC thresholds varied between 3.75 and $45 \mathrm{~dB}$ HL (median: $21.25 \mathrm{~dB}$ HL) but remained stable (i.e., had a threshold shift of less than $\pm 10 \mathrm{~dB}$ HL) throughout the study period in almost all subjects (Fig. 2; Skillings-Mack test: $\left.p_{\text {overall }}=0.455\right)$. In the 2 subjects where shifts of $>10 \mathrm{~dB}$ HL occurred, thresholds shifted to lower values (and thus better hearing). Average hearing thresholds in sound field decreased from $60.55 \mathrm{~dB}$ HL (SD: $12.55 \mathrm{~dB}$ HL; median: $62.5 \mathrm{~dB}$ HL) to $33.75 \mathrm{~dB}$ HL (SD: $8.23 \mathrm{~dB} \mathrm{HL}$; median: $29.38 \mathrm{~dB}$ HL) after 3 months (Fig. 3). After 6 months the mean threshold was $33.19 \mathrm{~dB}$ HL (SD: $7.71 \mathrm{~dB}$ HL; median: $31.25 \mathrm{~dB}$ HL). At both time frames, mean thresholds were significantly lower than before the intervention (Wilcoxon signed-rank test: pre vs. 3 months: $p_{\text {adj }}<0.001$; pre vs. 6 months: $\left.p_{\text {adj }}<0.0001\right)$ and did not change significantly between 3 and 6 months of follow-up ( $p_{\text {adj }}=$ 0.831 ). The mean functional gain after 6 months com- 

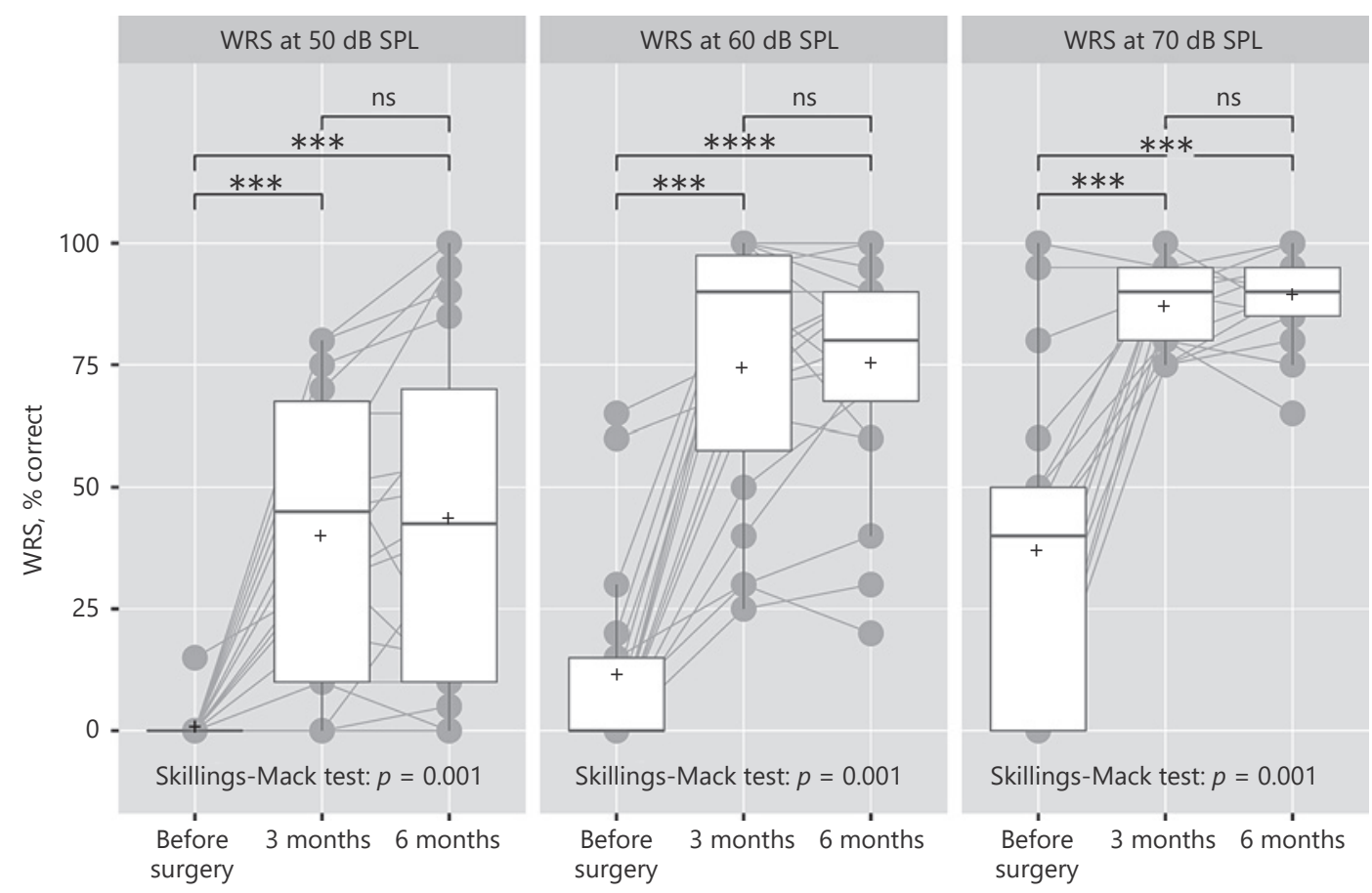

Fig. 4. Word recognition scores (WRS) over time at different sound pressure levels. Paired samples are connected by lines. Mean and median are given as crosses and horizontal lines, respectively. Boxes give 25 and $75 \%$ quartiles. Whiskers denote minimum/max-

imum values but do not include outliers, which are defined as values deviating more than \pm 1.5 times the interquartile range from the respective quartiles. ns, not significant; ${ }^{* * *} p \leq 0.001$; ${ }^{* * * *} p \leq$ 0.0001 .

pared to before surgery was $28.02 \mathrm{~dB} \mathrm{HL}(\mathrm{SD}=12.77)$. In all 3 level settings (50, 60, $70 \mathrm{~dB})$, WRS increased significantly from 0,43 and $62 \%$ before surgery to 40,74 and $87 \%$ after 3 months and 43,75 and $89 \%$ after 6 months of follow-up, respectively. As indicated in Figure 4, this corresponds to a statistically significant increase compared to before intervention. There was no significant correlation of aided WRS (at 6 months of follow-up) with preoperative BC thresholds (Fig. 5), indicating that the success of hearing rehabilitation with the Bonebridge is independent of a sensorineural hearing loss component at least up to $45 \mathrm{~dB}$ HL. Speech reception thresholds in noise decreased significantly from $11.54 \mathrm{~dB}$ SNR (signal-tonoise ratio; SD: $8.24 \mathrm{~dB}$ SNR; median: $12.8 \mathrm{~dB}$ SNR) before surgery to $0.28 \mathrm{~dB}$ SNR (SD: $7.12 \mathrm{~dB}$ SNR; median: $-1.1 \mathrm{~dB}$ SNR) at 6 months of follow-up (Fig. 6; Wilcoxon signed-rank test; $\left.p_{\text {adj }}<0.001\right)$. Detailed summary statistics for speech tests are given in the upper part of Table 2.

\section{Patient-Reported Outcomes}

The APHAB questionnaire showed an increase in QoL after implantation of the Bonebridge. Global scores de- creased significantly from $48.5 \%$ (SD: $16.9 \%$; median: $48.6 \%$ ) before surgery to $32 \%$ (SD: $17 \%$; median: $33.6 \%$ ) after 3 months and 29.6\% (SD: 17.7\%; median: 27.7\%) after 6 months of follow-up, respectively (Fig. 7a; Wilcoxon signed-rank test; pre vs. 3 months: $p_{\text {adj }}<0.01$; pre vs. 6 months: $\left.p_{\text {adj }}<0.01\right)$. There was no significant change between 3 and 6 months of follow-up ( 3 vs. 6 months: $p_{\text {adj }}<0.36$ ). Likewise, ease of communication, background noise and reverberation subscores decreased in the same way, indicating congruent improvement in these categories. No significant change was observed in the aversiveness subscore. More detailed summary statistics for APHAB scores are given in the lower part of Table 2.

\section{Discussion/Conclusions}

In general, results from this study confirm the effectiveness of the Bonebridge. The most important outcome is a very good audiological benefit (WRS at $70 \mathrm{~dB}$ SPL $>75 \%$ ) up to pre-operative BC of $45 \mathrm{~dB}$ (Fig. 5). This corroborates the effectiveness of the device over its full 
Fig. 5. Correlation of aided word recognition scores (WRS at 60 and $70 \mathrm{~dB}$ SPL) and pre-operative $\mathrm{BC}$ thresholds. The dashed line indicates $75 \%$ word recognition. PTA4, pure tone average $(0.5,1,2$ and $4 \mathrm{kHz})$.
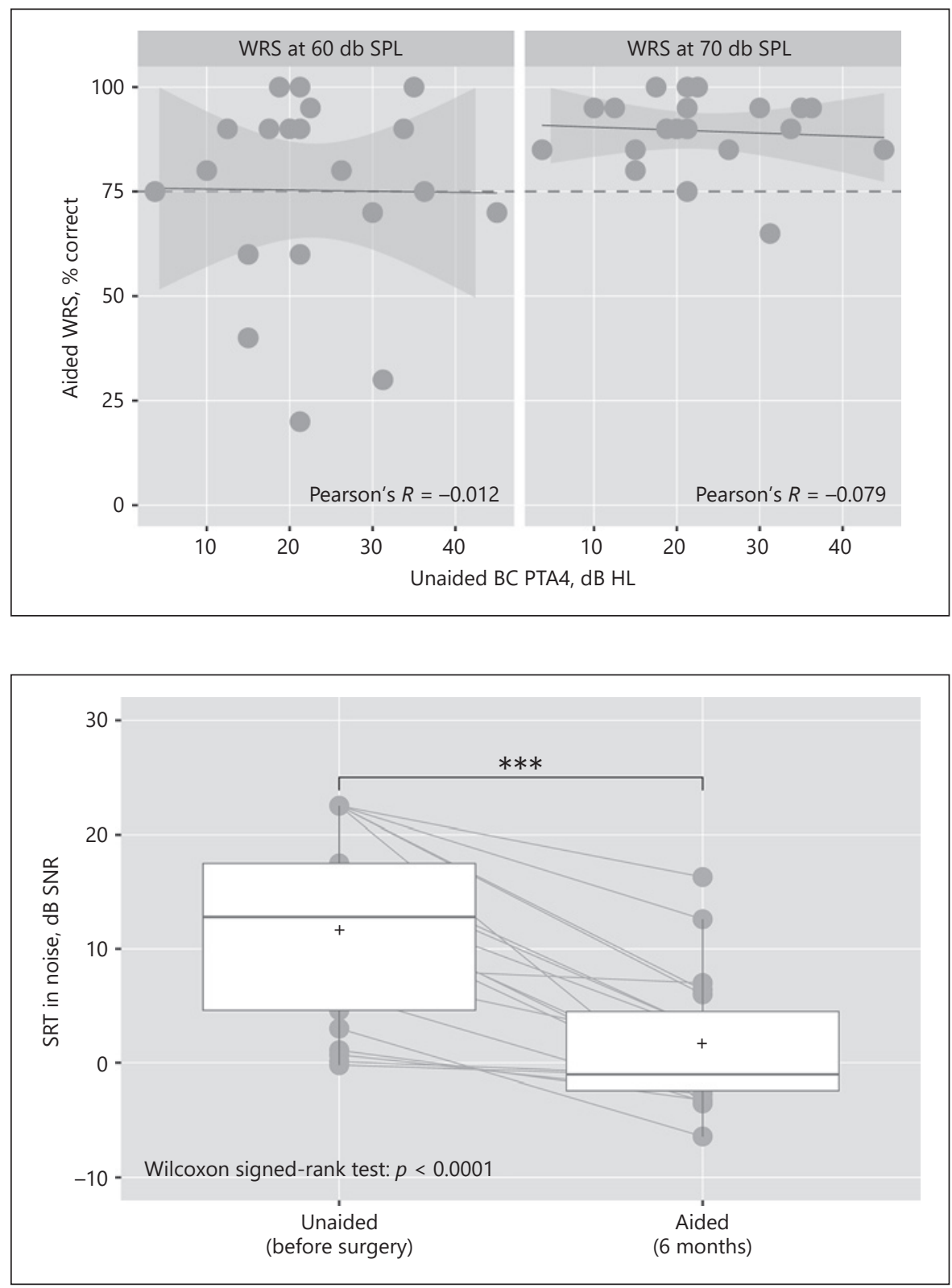

Fig. 6. Speech reception thresholds (SRT) in noise (SON0) before surgery and after 6 months of follow-up. Paired samples are connected by lines. Mean and median are given as crosses and horizontal lines, respectively. Boxes give 25 and $75 \%$ quartiles. Whiskers denote minimum/maximum values but do not include outliers, which are defined as values deviating more than \pm 1.5 times the interquartile range from the respective quartiles. SNR, signal-to-noise ratio. ${ }^{* * *} p \leq 0.001$. indication range. Mean functional gain in the study population was $28.02 \mathrm{~dB} \mathrm{HL}$, and this corresponds to results of many other studies where functional gain was reported from $24 \mathrm{~dB}$ up to $37 \mathrm{~dB}$ [Sprinzl et al., 2013; Rahne et al., 2015; Sprinzl and Wolf-Magele, 2016; Weiss et al., 2017b]. Furthermore, it is confirmed that there is no hearing deterioration in audiometric hearing results associated with this intervention.

From a surgical point of view, implants were positioned in the sinodural angle in all patients to reduce the risk of inference with the sigmoid sinus and dura mater. Some authors claim that under specific conditions, a retrosig- moidal approach is better, e.g., when the available area between sigmoid sinus and posterior wall of external meatus is too small due to radical cavities [Sprinzl and WolfMagele, 2016]. From personal experience and restricted available literature data [Lassaletta et al., 2016; Salcher et al., 2017] there is no evidence of negative side effects associated with dura or sinus compression. However, we followed the manufacturer's recommendation to avoid compression. Whenever drilling depth is an issue (as determined by CT scan) lifts can be used to safely position the BC-FMT in the mastoid bone. There are 4 sizes available $(1,2,3$ and $4 \mathrm{~mm})$. When 3 - or 4 -mm lifts are used, screws 
Table 2. Summary statistics of speech test results and quality of life outcomes at each time frame

\begin{tabular}{|c|c|c|c|c|c|c|}
\hline & Time frame & Unit & Mean & SD & Min. & Max. \\
\hline \multicolumn{7}{|l|}{ Speech test } \\
\hline WRS50 & Pre-operative & $\%$ & 0.02 & 0.06 & 0.00 & 0.25 \\
\hline WRS50 & 3 months FU & $\%$ & 0.40 & 0.31 & 0.00 & 0.80 \\
\hline WRS50 & 6 months FU & $\%$ & 0.42 & 0.36 & 0.00 & 1.00 \\
\hline WRS60 & Pre-operative & $\%$ & 0.45 & 0.38 & 0.00 & 1.00 \\
\hline WRS60 & 3 months FU & $\%$ & 0.74 & 0.27 & 0.25 & 1.00 \\
\hline WRS60 & 6 months FU & $\%$ & 0.72 & 0.26 & 0.15 & 1.00 \\
\hline WRS70 & Pre-operative & $\%$ & 0.64 & 0.36 & 0.00 & 1.00 \\
\hline WRS70 & 3 months FU & $\%$ & 0.87 & 0.09 & 0.75 & 1.00 \\
\hline WRS70 & 6 months FU & $\%$ & 0.88 & 0.11 & 0.55 & 1.00 \\
\hline SRT in noise & Pre-operative & dB SNR & 11.36 & 8.09 & -0.20 & 22.50 \\
\hline SRT in noise & 6 months FU & dB SNR & 0.41 & 6.98 & -14.10 & 16.30 \\
\hline \multicolumn{7}{|l|}{ APHAB score } \\
\hline Global & Pre-operative & $\%$ & 48.84 & 16.64 & 17.00 & 84.22 \\
\hline Global & 3 months FU & $\%$ & 32.03 & 17.06 & 3.44 & 69.11 \\
\hline Global & 6 months FU & $\%$ & 29.68 & 17.24 & 7.83 & 73.72 \\
\hline EC & Pre-operative & $\%$ & 42.44 & 23.00 & 6.50 & 82.83 \\
\hline $\mathrm{EC}$ & 3 months FU & $\%$ & 25.50 & 19.42 & 1.00 & 66.05 \\
\hline $\mathrm{EC}$ & 6 months FU & $\%$ & 22.55 & 16.79 & 4.67 & 63.67 \\
\hline $\mathrm{BN}$ & Pre-operative & $\%$ & 53.64 & 21.47 & 12.83 & 89.00 \\
\hline $\mathrm{BN}$ & 3 months FU & $\%$ & 39.05 & 20.52 & 4.67 & 80.83 \\
\hline $\mathrm{BN}$ & 6 months FU & $\%$ & 35.27 & 21.18 & 8.33 & 84.83 \\
\hline RV & Pre-operative & $\%$ & 49.48 & 17.35 & 17.17 & 89.00 \\
\hline RV & 3 months FU & $\%$ & 31.54 & 17.35 & 2.83 & 62.33 \\
\hline RV & 6 months FU & $\%$ & 31.07 & 17.46 & 8.67 & 72.67 \\
\hline AV & Pre-operative & $\%$ & 29.52 & 22.62 & 1.00 & 89.00 \\
\hline $\mathrm{AV}$ & 3 months FU & $\%$ & 34.59 & 24.85 & 1.00 & 89.00 \\
\hline $\mathrm{AV}$ & 6 months FU & $\%$ & 34.93 & 23.15 & 4.67 & 88.83 \\
\hline
\end{tabular}

WRS50/60/70, word recognition score at 50/60/70 dB SPL; FU, follow-up; SRT, speech reception threshold; SNR, signal-to-noise ratio; APHAB, Abbreviated Profile of Hearing Aid Benefit; EC, ease of communication; BN, background noise; RV, reverberation; AV, aversiveness to sound.

of adequate length ( 8 and $10 \mathrm{~mm}$, respectively) are included within the implant kit. Thirty-eight percent of patients implanted in this study group received BCI lifts, and there was no complication related to that after 6 months. Neither skin infections nor skin or bone overgrowth were observed. With other devices, the rates of these complications vary from 17.5 to 37\% [Granström et al., 2001; Lloyd et al., 2007; McDermott et al., 2009; Kraai et al., 2011; Van Rompaey et al., 2011]. The discharge of fluid observed in 3 patients was not related to the intervention but rather due to chronic $(n=1)$ or acute $(n=2)$ otitis media.

Regarding patient-reported outcomes, $\mathrm{APHAB}$ proved to be a very good tool for the assessment of hearing-related QoL in Bonebridge patients, as reported previously for other BCIs and middle-ear implants [Monini et al., 2017; Bosman et al., 2018]. The benefits in patient satisfaction are in line with hearing benefits as measured by functional gain, WRS and signal-to-noise ratio. Similar positive correlations have been reported in other studies on BCIs, hearing aids and cochlear implants [Ambert-Dahan et al., 2018; Giannantonio et al., 2018]. We want to emphasize the need for long-term observations and comparative designs in future studies on QoL associated with implantable hearing solutions.

Patient-reported outcomes should be considered when selecting among treatment options with equal audiological benefit. The Bonebridge provides significant audiological benefit for patients suffering from mixed and conductive hearing loss in both speech understanding in quiet and in noise. Together with a very low rate and minor nature of adverse events, it is an excellent solution for hearing rehabilitation in patients with mixed or 


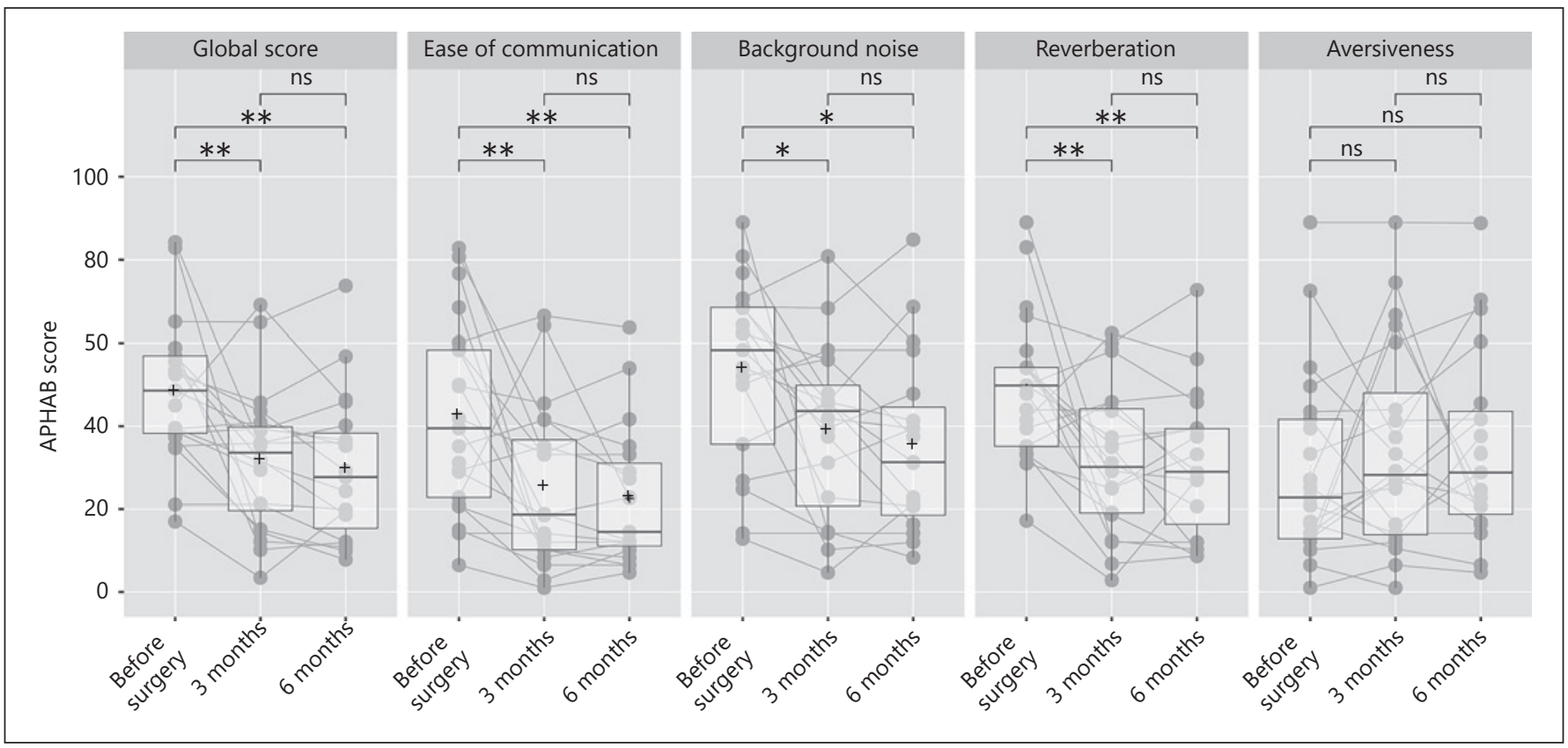

Fig. 7. QoL outcomes for the APHAB global score and four subscores. Mean and median are given as crosses and horizontal lines, respectively. Boxes give 25 and $75 \%$ quartiles. Whiskers denote minimum/maximum values but do not include outliers, which are

conductive hearing loss up to a BC threshold of $45 \mathrm{~dB}$ HL. Future studies should investigate the long-term effect of this device on the patient's QoL.

\section{Statement of Ethics}

Subjects have given their written informed consent. The study protocol has been approved by the research institute's committee on human research.

\section{Disclosure Statement}

The authors have no conflicts of interest to declare. defined as values deviating more than \pm 1.5 times the interquartile range from the respective quartiles. ns, not significant; ${ }^{*} p \leq 0.05$; $* * p \leq 0.01$.

\section{Funding Sources}

The authors received no financial support for research, authorship and/or publication of this article.

\section{Author Contributions}

P.H.S. and H.S. performed surgeries; P.H.S. and M.K. planned the study; P.H.S., B.K., K.O., K.C., A.S. and A.R. conducted the study; P.H.S., A.R. and M.K. wrote the main manuscript; all authors discussed the results and implications and commented on the manuscript at all stages.

\section{References}

Alzahrani M, Tabet P, Saliba I. Pediatric hearing loss: common causes, diagnosis and therapeutic approach. Minerva Pediatr. 2015 Feb; 67(1):75-90.

Ambert-Dahan E, Laouénan C, Lebredonchel M, Borel S, Carillo C, Bouccara D, et al. Evaluation of the impact of hearing loss in adults: validation of a quality of life questionnaire. Eur Ann Otorhinolaryngol Head Neck Dis. 2018 Feb;135(1):25-31.
Baumgartner WD, Hamzavi JS, Böheim K, WolfMagele A, Schlögel M, Riechelmann H, et al. A new transcutaneous bone conduction hearing implant: short-term safety and efficacy in children. Otol Neurotol. 2016 Jul;37(6):71320.

Bosman AJ, Kruyt IJ, Mylanus EA, Hol MK, Snik $\mathrm{AF}$. On the evaluation of a superpower sound processor for bone-anchored hearing. Clin Otolaryngol. 2018 Apr;43(2):450-5.
Braun T, Hempel JM, Berghaus A. Developmental disorders of the ear in children and adolescents: conservative and surgical treatment options. Dtsch Arztebl Int. 2014 Feb;111(6):92-8. Bravo-Torres S, Der-Mussa C, Fuentes-López E. Active transcutaneous bone conduction implant: audiological results in paediatric patients with bilateral microtia associated with external auditory canal atresia. Int J Audiol. 2018 Jan;57(1):53-60. 
Chatfield M, Mander A. The Skillings-Mack test (Friedman test when there are missing data). Stata J. 2009 Apr;9(2):299-305.

Cox RM, Alexander GC. The abbreviated profile of hearing aid benefit. Ear Hear. 1995 Apr; 16(2):176-86.

Gardner EK, Jackson CG, Kaylie DM. Results with titanium ossicular reconstruction prostheses. Laryngoscope. 2004 Jan;114(1):65-70.

Gavilan J, Adunka O, Agrawal S, Atlas M, Baumgartner WD, Brill S, et al. Quality standards for bone conduction implants. Acta Otolaryngol. 2015;135(12):1277-85.

Giannantonio S, Scorpecci A, Pacifico C, Marsella P. A functional and anatomical comparison between two passive transcutaneous bone conduction implants in children. Int J Pediatr Otorhinolaryngol. 2018 May;108:202-7.

Govil N, Kaffenberger TM, Shaffer AD, Chi DH. Factors influencing hearing outcomes in pediatric patients undergoing ossicular chain reconstruction. Int J Pediatr Otorhinolaryngol. 2017 Aug;99:60-5.

Granström G, Bergström K, Odersjö M, Tjellström A. Osseointegrated implants in children: experience from our first 100 patients. Otolaryngol Head Neck Surg. 2001 Jul;125(1): $85-92$.

Ihler F, Volbers L, Blum J, Matthias C, Canis M. Preliminary functional results and quality of life after implantation of a new bone conduction hearing device in patients with conductive and mixed hearing loss. Otol Neurotol. $2014 \mathrm{Feb} ; 35(2): 211-5$.

Kraai T, Brown C, Neeff M, Fisher K. Complications of bone-anchored hearing aids in pediatric patients. Int J Pediatr Otorhinolaryngol. 2011 Jun;75(6):749-53.

Laske RD, Röösli C, Pfiffner F, Veraguth D, Huber AM. Functional Results and Subjective Benefit of a Transcutaneous Bone Conduction Device in Patients With Single-Sided Deafness. Otol Neurotol. 2015 Aug;36(7): 1151-6.

Lassaletta L, Calvino M, Zernotti M, Gavilán J. Postoperative pain in patients undergoing a transcutaneous active bone conduction im- plant (Bonebridge). Eur Arch Otorhinolaryngol. 2016 Dec;273(12):4103-10.

Lloyd S, Almeyda J, Sirimanna KS, Albert DM, Bailey CM. Updated surgical experience with bone-anchored hearing aids in children. J Laryngol Otol. 2007 Sep;121(9):826-31.

McDermott AL, Williams J, Kuo M, Reid A, Proops D. The birmingham pediatric boneanchored hearing aid program: a 15-year experience. Otol Neurotol. 2009 Feb;30(2):17883.

Monini S, Bianchi A, Talamonti R, Atturo F, Filippi C, Barbara M. Patient satisfaction after auditory implant surgery: ten-year experience from a single implanting unit center. Acta Otolaryngol. 2017 Apr;137(4):389-97.

Nadaraja GS, Gurgel RK, Kim J, Chang KW. Hearing outcomes of atresia surgery versus osseointegrated bone conduction device in patients with congenital aural atresia: a systematic review. Otol Neurotol. 2013 Oct; 34(8):1394-9.

Olszewski L, Jedrzejczak WW, Piotrowska A, Skarzynski H. Round window stimulation with the Vibrant Soundbridge: comparison of direct and indirect coupling. Laryngoscope. 2017 Dec;127(12):2843-9.

R Core Team. R: A language and environment for statistical computing. Vienna, Austria: R Foundation for Statistical Computing; 2015.

Rahne T, Seiwerth I, Götze G, Heider C, Radetzki F, Herzog M, et al. Functional results after Bonebridge implantation in adults and children with conductive and mixed hearing loss. Eur Arch Otorhinolaryngol. 2015 Nov; 272(11):3263-9.

Ratuszniak A, Mrówka M, Skarżyński PH. Urządzenia wszczepialne na przewodnictwo kostne - zasada działania oraz wskazania [The implantable bone conduction devices operating principles and indications]. Nowa Audiofonologia. 2017;6:29-34.

Riss D, Arnoldner C, Baumgartner WD, Blineder M, Flak S, Bachner A, et al. Indication criteria and outcomes with the Bonebridge transcutaneous bone-conduction implant. Laryngoscope. 2014 Dec;124(12):2802-6.
Salcher R, Zimmermann D, Giere T, Lenarz T, Maier H. Audiological results in SSD with an active transcutaneous bone conduction implant at a retrosigmoidal position. Otol Neurotol. 2017 Jun;38(5):642-7.

Schmerber S, Deguine O, Marx M, Van de Heyning P, Sterkers O, Mosnier I, et al. Safety and effectiveness of the Bonebridge transcutaneous active direct-drive bone-conduction hearing implant at 1-year device use. Eur Arch Otorhinolaryngol. 2017 Apr;274(4):1835-51.

Sprinzl G, Lenarz T, Ernst A, Hagen R, WolfMagele A, Mojallal H, et al. First European multicenter results with a new transcutaneous bone conduction hearing implant system: short-term safety and efficacy. Otol Neurotol. 2013 Aug;34(6):1076-83.

Sprinzl GM, Wolf-Magele A. The Bonebridge Bone Conduction Hearing Implant: indication criteria, surgery and a systematic review of the literature. Clin Otolaryngol. 2016 Apr; 41(2):131-43.

Van Rompaey V, Claes G, Verstraeten N, van Dinther J, Zarowski A, Offeciers E, et al. Skin reactions following BAHA surgery using the skin flap dermatome technique. Eur Arch Otorhinolaryngol. 2011 Mar;268(3):373-6.

Wazen JJ, Wycherly B, Daugherty J. Complications of bone-anchored hearing devices. Adv Otorhinolaryngol. 2011;71:63-72.

Weiss BG, Bertlich M, Scheele R, Canis M, Jakob M, Sohns JM, et al. Systematic radiographic evaluation of three potential implantation sites for a semi-implantable bone conduction device in 52 patients after previous mastoid surgery. Eur Arch Otorhinolaryngol. 2017a Aug;274(8):3001-9.

Weiss R, Leinung M, Baumann U, Weißgerber T, Rader T, Stöver T. Improvement of speech perception in quiet and in noise without decreasing localization abilities with the bone conduction device Bonebridge. Eur Arch Otorhinolaryngol. 2017b May;274(5):2107-15.

Wickham H. ggplot2: elegant graphics for data analysis [Internet]. New York: Springer; 2009 [cited 2018 Sep 14]. Available from: //www. springer.com/us/book/9780387981413 